medRxiv preprint doi: https://doi.org/10.1101/2020.10.07.20166769; this version posted October 9, 2020. The copyright holder for this preprint (which was not certified by peer review) is the author/funder, who has granted medRxiv a license to display the preprint in It is made available under a CC-BY-NC-ND 4.0 International license .

\title{
Hepatic resection versus transarterial chemoembolization for the intermediate-stage hepatocellular carcinoma : a predicted mortality risk-based decision analysis
}

Linbin $\mathrm{Lu}$

Department of Oncology, the 900th Hospital of Joint Logistic Support Force, PLA, Fuzong Clinical College of Fujian Medical University, 350025, Fuzhou, Fujian, PR China

Running head: Hepatectomy vs TACE for liver cancer

\section{Synopsis:}

- The line of HR and TACE was crossing with predicted OM risk at $100 \%$

- The benefit of HR versus TACE decreased progressively as predicted OM risk $>55 \%$

- When OM risk $>80 \%$, HR was not significantly superior to TACE 
medRxiv preprint doi: https://doi.org/10.1101/2020.10.07.20166769; this version posted October 9, 2020. The copyright holder for this preprint (which was not certified by peer review) is the author/funder, who has granted medRxiv a license to display the preprint in It is made available under a CC-BY-NC-ND 4.0 International license .

\begin{abstract}
Background: The selection criterion for hepatic resection(HR) in intermediate-stage(IM) hepatocellular carcinoma(HCC) is still controversial. This study aims to compare transarterial chemoembolisation (TACE) and HR in the range of predicted overall mortality(OM).

Methods: In all, 946 consecutive patients with IM-HCC were categorised in HR and TACE group. We performed multivariable Cox regression model to predict OM in HR patients. To evaluate the HR impact on OM concerning baseline characteristics, we test the interaction between predicted OM risk and HR status. The cut-off values were determined by two-piece-wise linear regression model and decision curve analysis. Also, the inverse probability of treatment weight was performed to minimise potential bias as a sensitivity analysis.

Findings: Totally, $23.0 \%(\mathrm{n}=225)$ of patients received HR. The 5 -yr overall survival rate was higher in the HR group versus the TACE group $(52.3 \%$ vs $22.8 \%$; $<0.0001)$. In the HR group, five predictors $($ all $<0.05)$ were selected to calculate the 5 -yr OM risk. This model also used to predict the 5-yr OM-free survival rate. The line of HR and TACE was crossing with predicted OM risk at $100 \%$. The benefit of HR versus TACE decreased progressively as predicted OM risk $>55 \%$. When OM risk $>80 \%$, HR was not significantly superior to TACE (HR:0.61;95\%CI:0.31,1.21), and both HR and TACE did not increase net benefit.

Interpretation: Hepatic resection was superior to transarterial chemoembolisation for intermediate-stage hepatocellular carcinoma at the 5-yr OM risk $<80 \%$. And TACE was suitable for the patients with OM risk $>80 \%$.
\end{abstract}

Funding: none.

Keyword: hepatic resection, intermediate-stage hepatocellular carcinoma, transarterial chemoembolization, overall mortality, real-world study 


\section{Introduction}

Hepatocellular carcinoma $(\mathrm{HCC})$ is one of the most leading cause of cancer-related death worldwide and the fifth cause of death in China ${ }^{1}$. According to the BCLC staging system, the most widely used scheme, patients with early stages(stage 0 and A) are suitable for hepatic resection(HR), while intermediate-stage(IM) HCC patients are recommended for transarterial chemoembolization(TACE) ${ }^{2}$. When compared with conservative treatment for IM-stage(stage B) HCC, patients treated with TACE have better 2-year overall survival ${ }^{3}$. After selected by the Bolondi's criteria ${ }^{4}$, the patients with stage B1 or B2 have a higher 5-year survival rate $(21.4 \% \text { vs } 13.9 \%)^{5}$. Subsequently, the subgroup of IM-stage HCC patients who benefit from TACE was identified through numerous criteria, including the ART score $^{6}$, ABCR score ${ }^{7}$, the ALBI grade ${ }^{8}$, etc. Although the highly selected HCC patients have a median survival of 51.5 months $^{9}$, the role of TACE is being challenged by hepatic resection(HR).

Recently, a meta-analysis including 18 high-quality studies is performed to compared survival outcomes of 5,986 patients after HR and TACE. They find that both stage B and stage $\mathrm{C}$ patients show significantly better overall survival (OS) for HR compared to TACE ${ }^{10}$. However, the controversial evidence has emerged that HR is superior to TACE only in the lower mortality risk subgroup of IM-stage HCC ${ }^{11-15}$, such as BCLC stage B1/B2 ${ }^{12,13}$. Although the subgroup of IM-stage HCC has been selected by the predicted models ${ }^{16}$ with median overall survival of 61.3 months, patients who are more suitable for HR is still controversial. Interestingly, Cucchetti et $\mathrm{al}^{17}$ perform a regret-based decision curve analysis (Regret-DCA) to choose HR or TACE for IM-stage HCC. In this study, HR should be offered to the patients with $3 \mathrm{yr}$ mortality risk $<35 \%$, but the optimal strategy(HR vs TACE) is still unclear when mortality risk between $35 \%$ and $70 \%$. To deal with this issue, we construct a predicted mortality risk-based decision analysis to compare hepatic resection and transarterial chemoembolization in the intermediate-stage hepatocellular carcinoma,

\section{Methods and patients}

\subsection{Patient selection}

Clinical and biological data in our study had been previously published in full ${ }^{18}$. In this study, we mainly focus on the derivation cohort from Sun Yat-sen University Cancer Center(SYSUCC) between January 2007 and May 2012. The details of inclusion criteria were shown in Fig S1. A total of 979 patients were included in the derivation cohort. In the derivation cohort, 37(37/979, 3.8\%) patients were excluded for refusing to received treatment and 942 patients were included into final analysis, with TACE $(n=717,73.2 \%)$ or surgical resection $(n=225,23.0 \%)$ as their first-line treatment. According to the decision form multidisciplinary teams, the subsequent therapies include ablative therapies $(\mathrm{n}=94 / 805,11.7 \%)$, surgical resection $(\mathrm{n}=43 / 805,5.3 \%)$, repeated TACE $(\mathrm{n}=235 / 805,29.2 \%)$, targeted therapies $(\mathrm{n}=6 / 805,0.7 \%)$, or best supportive care $(\mathrm{n}=427 / 805,53.0 \%)$.

The study protocol (2017-FXY-129) was approved by the Ethics Committee of SYSUCC and another three medical centres. Because this was a retrospective study, the informed consent was waived.

\subsection{Diagnosis, treatment and follow-up}

For the patients treated with HR, HCC diagnosis was confirmed by histopathological examination of surgical samples. For the patients with TACE, in contrast, the diagnosis was confirmed by the combination with the serum level of alpha-fetoprotein(AFP, over than $400 \mathrm{ng} / \mathrm{mL}$ ) and clinical imaging, 
including ultrasonography, computed tomography, or magnetic resonance imaging. If the diagnosis was uncertain based on imaging and AFP level, a needle biopsy was performed.

Based on the decision from the multidisciplinary teams, the optimal treatment plans were adopted for each HCC patient. Indications for HR in the IM-HCC patients were the presence of appropriate residual liver volume determined by computed tomography. For the patients without cirrhosis, $30 \%$ remnant liver volume after HR was considered adequate. For those with chronic hepatitis, cirrhosis, and severe fatty liver, however, the remnant volume should be more than $50 \%$. Liver resection should not be carried out among the patients with intermediate or advanced cirrhosis and poor liver function(Child-Pugh C). Patients who satisfied the indications for HR were treated by surgical resection unless the patient requested TACE.

During the period of initial treatment for the first 2 years, patients were followed up for every 2 or 3 months if complete remission was achieved. The frequency gradually decreased to every 3 to 6 months after 2 years' remission.

\subsection{Variables and definition}

Patients were stratified as the group of hepatic resection(HR) and transarterial chemoembolisation (TACE). HR was defined as surgical therapy for the lesions in hepatic segments or lobes. In the clinical, patients with well liver function and less tumour loading were usually suitable for HR. TACE was defined as chemoembolisation of the hepatic artery. Continuous variables included age, the diameter of the main tumour, alpha-fetoprotein(AFP), prothrombin time(PT), total bilirubin(TBLT) at diagnosis. AFP and TBLT were transformed to the $\log _{10}$ scale because of their left skew. Categorical variables consisted of gender (female and male), No. of intrahepatic lesions $(\leq 3,>3)$, both lobe with lesions(no, yes). All variables were afforded before any anti-cancer treatment. The endpoint of interest was overall mortality at $5 \mathrm{yr}$.

\subsection{Statistical analyses}

To compare differences of baseline characteristics between the HR and TACE groups, we compared categorical variables with the chi-square test and continuous variables by the Mann-Whitney test.

To test the OM-free survival between HR and TACE in the range of OM risk, we divide the statistical analyses into two main parts.

Firstly, Kaplan-Meier methods were used to calculate OM-free survival rates for the HR and TACE cohorts. Also, we employed multivariable Cox regression(MVR) to develop the MVR model. In this study, the covariates(all $\mathrm{p}<0.05$ between two groups) list in Table 1 were used to build the MVR mode ${ }^{18}$, including the continuous covariates of age, PT and diameter of the main tumour, as well as the categorical covariates No. of intrahepatic lesions, both lobe with lesions. To assess discrimination of the model, the area under the receiver operating characteristic curve (AUC) was calculated. Besides, through decision curve analysis, we calculated the net benefit of the model and determined the cut-off value through two reference strategies(test none or test all).

Secondly, to evaluate the interaction between HR and OM risk, we used the method ${ }^{20}$ as follow: (1)we used Model I to test the association between OM and covariates in HR patients. From this model, OM-risk at $5 \mathrm{yr}$ was predicted to establish a baseline OM risk for both HR and TACE cohort, (2) this predicted OM risk was added as a covariate to a second multivariate Cox model to calculate the predicted probability of survival at $5 \mathrm{yr}$, and (3) interaction between HR and OM risk was graphed using spline smoothing based on generalised additive model. Furthermore, a two-piece-wise linear 
regression and the recursive method was performed to calculate the inflexion point of the TACE line, and a log-likelihood ratio test was used to compare the one-line linear regression.

We performed the number needed to treat (NNT) analysis to explore how the NNT varies with predicted OM risk at 5yr. Stratified analysis was performed to examine the hazard ratio(vs TACE) for each different $20 \%$ proportion based on 5-yr predicted OM-risk. Meanwhile, the 5-yr observed survival probability of TACE cohort was estimated by the Kaplan-Meier curve. Then, we calculate NNT by the formulas of Altman and Andersen ${ }^{21}$.

\subsection{Sensitivity analysis}

Finally, we conducted a sensitivity analysis using inverse probability of treatment weight (IPTW) to eliminate inherent differences between two groups. The propensity score(PS) was estimated as the predicted probability of treating with HR in each patient. IPTW was then calculated as the inverse of the PS for HR patients and as the inverse of (1-PS) for the TACE patients. To eliminate the effect of ablative therapies and surgical resection after first-line treatment, we builded a secondary cohort without those therapies. All the analyses mentioned in the second step were repeated in the IPTW and secondary cohort.

Statistical analysis was performed using Empower (www.empowerstats.com, X\&Y solutions, inc. Boston MA) and R software (version 3.4.3). P-value $<0.05$ considered significant.

\section{Results}

\subsection{Descriptive characteristics}

After excluding those who refused to receive treatment(n=33), a total of $942 \mathrm{HCC}$ patients were included into the derivation cohort, with a median age of 53.9 (SD, 12.3) years for TACE group $(\mathrm{n}=717)$, and 50.9(SD, 12.6) years for HR group $(\mathrm{n}=225)$. After first-line treatment with TACE, 46 patients $(6.6 \%, 46 / 597)$ had the invasion of portal vein or its branch $(n=38)$, hepatic veins $(n=6)$ and Vena Canva/Atrium(n=2), 53 patients $(8.9 \%, 53 / 597)$ with distant metastasis, while 36 patients $(6.0 \%$, 36/597) with lymph node metastasis at the second follow-up visit. Besides, for the HR group, 11 patients $(5.3 \%, 11 / 208)$ had the invasion of portal vein or its branch, 16 patients $(7.7 \%, 16 / 208)$ with distant metastasis, while 4 patients $(1.9 \%, 4 / 208)$ with lymph node metastasis.

In the derivation cohort, patients with HR were younger, higher PT value, the shorter diameter of the main tumour, less frequently No. of intrahepatic lesions and both lobe with lesions(all $\mathrm{p}<0.05$ ), which was shown in Table 1. The majority of the patient $(825 / 942,87.6 \%)$ had hepatitis B virus(HBV) infection, who treated with nucleos(t)ide analogue therapy. The difference of HBV infection rate was not significant between HR and TACE group.

\subsection{Survival analysis for the entire cohort}

As was shown in Fig 1, the mOS is $18.5(95 \% \mathrm{CI}: 16.9,20.3)$ month for TACE group versus 67.4(95\%CI:46.7, 88.1) for HR group ( $<<0.0001)$. The median overall survival(mOS) for the entire cohort was 23.7 (95\%CI:20.4, 27.2) month. There were 89 cases $(89 / 942,9.4 \%)$ still at risk at $5 \mathrm{yr}$. At $5 \mathrm{yr}$, OM-free survival rates was 30.6\% (95\%CI: $27.0 \%, 34.6 \%$ ) for the entire cohort, and it was $52.3 \%$ $(95 \%$ CI: $44.9 \%, 61.0 \%)$ for HR group versus $22.8 \%(95 \% \mathrm{CI}: 19.0 \%, 27.4 \%)$ for the TACE group (p $<$ $0.0001)$.

In multivariable analysis focusing on the entire cohort (Table 2), age(HR,1.00; 95\%CI: 0.99, 1.01), PT(HR,1.07; 95\%CI:1.00, 1.14), diameter of main tumor(HR,1.15; 95\%CI:1.13, 1.18), No. of 
intrahepatic lesions(HR,1.12; 95\%CI:0.80, 1.57 for 3 vs 2; HR,1.59;95\%CI:1.31, 1.93 for $>3$ vs 2 , respectively), both lobe with lesions(HR,1.51; 95\%CI:1.26, 1.80) were identified as the predictor for the MVR model. By decision curve analysis, we found that none could receive a net benefit from HR and TACE for OM risk $>80 \%$; maximal utility occurred at 55\%(Fig S2).

Next, the predictors in MVR model were used to predict 5-yr OM risk and OM-free survival rate for the entire cohort. The predict OM risk was plotted against OM-free survival, and the lines for HR and TACE crossed at $100 \%(\mathrm{Fig} 2)$. Consistent with the maximal utility point of DCA, the inflexion point of TACE line was calculated at $55 \%(\mathrm{p}<0.001$, Table 3$)$, indicating the benefit from HR decreased progressively as predicted OM risk $>55 \%$. Interestingly, the predicted survival rate of TACE line at $55 \%$ was $20 \%(95 \% \mathrm{CI}: 19 \%, 22 \%)$, which was in the interval of observed OM-free survival at $5 \mathrm{yr}$ for TACE group( $22.78 \%, 95 \%$ CI: $18.96 \%, 27.37 \%)$.

Fig 3 showed the results of NNT analysis. After incorporating the missing data into the group of $40-50 \%$ (Table S1), hazard ratios were $0.40(95 \% \mathrm{CI}: 0.26,0.61), 0.41(95 \% \mathrm{CI}: 0.28,0.60)$, $0.40(95 \% \mathrm{CI}: 0.24,0.68)$ and $0.61(95 \% \mathrm{CI}: 0.31,1.21)$ for each group. According to the formulas, NNT was not significantly available at the group of OM risk $>80 \%$.

\subsection{Sensitivity analysis}

The details of results after IPTW and secondary cohort were shown in Supplementary Appendix A and B. All results from the IPTW and secondary cohort were similar to the derivation cohort.

\section{Discussion}

In this large-scale, real-world data, the 5-yr OM-free survival curve of HR and TACE were comparing in predicted OM risk for the range of $20 \%-100 \%$. We found that the overall survival for HR was significantly better than their TACE counterparts, which was consistent with previous literature ${ }^{10,22}$ However, the net benefit from HR decreased progressively as predicted OM risk $>55 \%$. When OM risk $>80 \%$, HR was not significantly superior to TACE for the patients with BCLC-B HCC, and both HR and TACE did not increase net benefit. To best of our knowledge, we first defined the predicted mortality risk-based decision analysis to select the optimal therapy.

Our study had several important findings. When compared with TACE group, we found that the benefit from HR was nonlinearly associated with baseline 5-yr OM risk; maximal net benefit occurred at $55 \%$. In 2015, Colombo et al ${ }^{23}$ had come up with an assumption that intermediate-stage HCC patients could still be suitable for liver resection if the 5-yr survival rate reached $50 \%$. Our findings primarily validated this hypothesis. In line with previous literatures ${ }^{13,14}$, we identified a subgroup with OM risk $<80 \%$, in which patients treated with HR had significantly better overall survival than TACE group. Based on the Bolondi's sub-staging model ${ }^{4}$, Wei et $\mathrm{al}^{13}$ the postoperative 5 -yr survival rate for patients in the BCLC B1-B3 stage was $49.5 \%, 33.7 \%$ and $12.9 \%$, respectively. But only the patients with $\mathrm{BCLC} \mathrm{B} 1 / \mathrm{B} 2$ had an optimal long-term survival than TACE group. In another large-scale study ${ }^{14}$, the benefit from liver resection was observed in the patients of BCLC-B1/B2 but not B3/B4.

Surprisingly, we also found an increase of $1 \%$ mortality rate(HR:1.01;95\%CI:0.72,1.72) from hepatic resection in OM risk for the range of $80 \%-100 \%$ in IPTW cohort but not significantly(Fig A3). In a high-quality meta-analysis ${ }^{10}$, the 5 -yr survival rate of advanced-stage $\mathrm{HCC}$ in the TACE group range from $0 \%$ to $21 \%$. It implied that the subgroup of $80 \%-100 \%$ OM risk might be contained in the 
medRxiv preprint doi: https://doi.org/10.1101/2020.10.07.20166769; this version posted October 9,2020 . The copyright holder for this preprint (which was not certified by peer review) is the author/funder, who has granted medRxiv a license to display the preprint in It is made available under a CC-BY-NC-ND 4.0 International license .

BCLC-C HCC patients. Therefore, TACE may be more suitable for patients with OM risk $>80 \%$.

Our study had some strengths, including providing the cut-off accuracy value to evaluate the tumour loading. Specifically, in our study, the survival rates between HR and TACE were compared in the vast and continuous range, so that the exact cut-off values could be calculated. Besides, because the cases in our study had already been treated, the selected bias was avoided. When evaluating the role of liver resection among patients with anatomically resectable tumour and well liver function, the randomized control trial was obviously against medical ethics. Therefore, the predicted mortality risk-based decision analysis for the real-world data may be a better choice.

Our study also had several limitations. Firstly, this was a retrospective cohort from real-world data, residual bias, and unmeasured confounders were unavoidable, even if we had used the inverse probability of treatment weight to eliminate inherent differences between two groups. Secondly, the patients in this study were from Sun Yat-sen University Cancer Center, one of the top-level hospitals of China. Our conclusions might be not suitable for patients in primary healthcare organizations. Besides, the leading cause of HCC in the Chinese populations was HBV-associated cirrhosis and non-alcoholic fatty liver disease in the western country. Whether the liver resection was superior to TACE in western populations was still unknown. Thirdly, the percentage of resectable HCC patients in the TACE group with 5 -yr OM risk $<80 \%$ were unclear. However, it was worthy of note that the potential unresectable HCC patients treated with TACE resulting from such errors would bias toward to the null and lead to an underestimation of the net benefit from liver resection versus TACE.

In the future, more attention should be caught to find the optimised combinations in the patients with $5 \mathrm{yr}$ OM risk $<80 \%$, such as hepatic resection, TACE, local ablation. Besides, for the intermediate-stage $\mathrm{HCC}$ with $\mathrm{OM}$ risk $>80 \%$, TACE combined with targeted drugs ${ }^{24}$ or immunotherapy may the promising selection.

Declaration of interests: The authors have no conflicts of interest.

\section{Acknowledgements}

We gratefully thank the statistical support from Empower $U$ team of the Department of Epidemiology and Biostatistics, X\&Y solutions Inc. in Boston. 


\section{Reference}

1. M Z, H W, X Z, et al. Mortality, morbidity, and risk factors in China and its provinces, 1990-2017: a systematic analysis for the Global Burden of Disease Study 2017. Lancet (London, England) 2019; 394(10204): 1145-58.

2. Llovet JM, Bru C, Bruix J. Prognosis of hepatocellular carcinoma: the BCLC staging classification. Seminars in liver disease 1999; 19(3): 329-38.

3. J B, JM L. Prognostic prediction and treatment strategy in hepatocellular carcinoma. Hepatology (Baltimore, Md) 2002; 35(3): 519-24.

4. Bolondi L, Burroughs A, Dufour JF, et al. Heterogeneity of patients with intermediate (BCLC B) Hepatocellular Carcinoma: proposal for a subclassification to facilitate treatment decisions. Seminars in liver disease 2012; 32(4): 348-59.

5. Wang JH, Kee KM, Lin CY, et al. Validation and modification of a proposed substaging system for patients with intermediate hepatocellular carcinoma. Journal of gastroenterology and hepatology 2015; 30(2): 358-63.

6. Hucke F, Sieghart W, Pinter M, et al. The ART-strategy: sequential assessment of the ART score predicts outcome of patients with hepatocellular carcinoma re-treated with TACE. J Hepatol 2014; 60(1): 118-26.

7. Adhoute X, Penaranda G, Naude S, et al. Retreatment with TACE: the ABCR SCORE, an aid to the decision-making process. J Hepatol 2015; 62(4): 855-62.

8. Pinato DJ, Sharma R, Allara E, et al. The ALBI grade provides objective hepatic reserve estimation across each BCLC stage of hepatocellular carcinoma. J Hepatol 2017; 66(2): 338-46.

9. Kim JH, Shim JH, Lee HC, et al. New intermediate-stage subclassification for patients with hepatocellular carcinoma treated with transarterial chemoembolization. Liver Int 2017; 37(12): 1861-8.

10. Hyun $\mathrm{MH}$, Lee YS, Kim JH, et al. Hepatic resection compared to chemoembolization in intermediate- to advanced-stage hepatocellular carcinoma: A meta-analysis of high-quality studies. Hepatology 2018; 68(3): 977-93.

11. Tada T, Kumada T, Toyoda H, et al. Role of hepatic resection in patients with intermediate-stage hepatocellular carcinoma: A multicenter study from Japan. Cancer science 2017; 108(7): 1414-20.

12. Zhaohui Z, Shunli S, Bin C, et al. Hepatic Resection Provides Survival Benefit for Selected Intermediate-Stage (BCLC-B) Hepatocellular Carcinoma Patients. Cancer Res Treat 2019; 51(1): 65-72.

13. Wei WX, Yang ZS, Lu LH, et al. Long-term survival after partial hepatectomy for sub-stage patients with intermediate stage hepatocellular carcinoma. International journal of surgery (London, England) 2018; 56: 256-63.

14. Kariyama K, Nouso K, Wakuta A, et al. Treatment of Intermediate-Stage Hepatocellular Carcinoma in Japan: Position of Curative Therapies. Liver Cancer 2020; 9(1): 41-9.

15. Chen S, Jin H, Dai Z, et al. Liver resection versus transarterial chemoembolization for the treatment of intermediate-stage hepatocellular carcinoma. Cancer Med 2019; 8(4): 1530-9.

16. Zhang YF, Zhou J, Wei W, et al. Intermediate-stage hepatocellular carcinoma treated with hepatic resection: the NSP score as an aid to decision-making. British journal of cancer 2016; 115(9): 1039-47.

17. Cucchetti A, Djulbegovic B, Tsalatsanis A, et al. When to perform hepatic resection for intermediate-stage hepatocellular carcinoma. Hepatology 2015; 61(3): 905-14.

18. Shen L, Zeng Q, Guo P, et al. Dynamically prognosticating patients with hepatocellular carcinoma through survival paths mapping based on time-series data. Nature communications 2018; 9(1): 2230. 
medRxiv preprint doi: https://doi.org/10.1101/2020.10.07.20166769; this version posted October $9,2020$. The copyright holder for this preprint (which was not certified by peer review) is the author/funder, who has granted medRxiv a license to display the preprint in It is made available under a CC-BY-NC-ND 4.0 International license .

19. Loppenberg B, Dalela D, Karabon P, et al. The Impact of Local Treatment on Overall Survival in Patients with Metastatic Prostate Cancer on Diagnosis: A National Cancer Data Base Analysis. Eur Urol 2017; 72(1): 14-9.

20. N F, QD T, J S, et al. Identifying optimal candidates for local treatment of the primary tumor among patients diagnosed with metastatic prostate cancer: a SEER-based study. European urology 2015; 67(1): 3-6.

21. Altman DG, Andersen PK. Calculating the number needed to treat for trials where the outcome is time to an event. Bmj 1999; 319(7223): 1492-5.

22. Liang L, Xing H, Zhang H, et al. Surgical resection versus transarterial chemoembolization for BCLC intermediate stage hepatocellular carcinoma: a systematic review and meta-analysis. HPB: the official journal of the International Hepato Pancreato Biliary Association 2018; 20(2): 110-9.

23. Colombo M, Sangiovanni A. Treatment of hepatocellular carcinoma: beyond international guidelines. Liver Int 2015; 35 Suppl 1: 129-38.

24. Kudo M, Ueshima K, Chan S, et al. Lenvatinib as an Initial Treatment in Patients with Intermediate-Stage Hepatocellular Carcinoma Beyond Up-To-Seven Criteria and Child-Pugh A Liver Function: A Proof-Of-Concept Study. Cancers 2019; 11(8).

\section{Figure legends}

Fig 1. Kaplan-Meier curves of overall survival in the derivation cohort stratified with hepatic resection and transarterial chemoembolisation. The median overall survival is $18.5(95 \% \mathrm{CI}: 16.9$, 20.3) month for TACE group versus $67.4(95 \% \mathrm{CI}: 46.7,88.1)$ for HR group $(\mathrm{p}<0.0001)$.

Fig 2. Overall mortality (OM)-free survival rate plotted against predicted probability of OM at $5 \mathbf{y r}$. Blue line indicates hepatic resection for primary treatment. Red line indicates TACE for primary treatment. Dashed line indicates observed OM-free survival at 5yr for TACE group(22.78\%, 95\%CI: 18.96\%, 27.37\%). The inflexion point of TACE line was calculated at 55\%.

Fig 3. Hazard ratio and Number Needed to Treat with hepatic resection(vs TACE) plotted against the predicted probability of $\mathrm{OM}$ at $5 \mathrm{yr}$ in the derivation cohort. 
medRxiv preprint doi: https://doi.org/10.1101/2020.10.07.20166769; this version posted October 9, 2020. The copyright holder for this preprint (which was not certified by peer review) is the author/funder, who has granted medRxiv a license to display the preprint in It is made available under a CC-BY-NC-ND 4.0 International license .

\section{Supplemental materials}

Table S1. The stratified analysis of predicted OM risk at 5yr before/after incorporating the missing data. Mode $1 \mathrm{I}$ showed the missing data were regarded as a independent group. Model II showed the missing data were incorporated into the group of $40-50 \%$.

Fig S1. Inclusion criteria of hepatocellular carcinoma patients. SYSUCC $=$ Sun Yat-sen University Cancer Center. HCC=hepatocellular carcinoma.

Fig S2. Net benefit curves for the multivariable Cox regression model. The y-axis measures standardized net benefit. The maximal net benefit occurred at 0.55 .

Table A1. The multivariable analysis focusing on the IPTW cohort. AFP=alpha-fetoprotein, $\mathrm{PT}=$ prothrombin time, $\mathrm{TBLT}=$ total bilirubin, $\mathrm{ALB}=$ albumin, $\mathrm{HR}=$ hepatic resection.

Table A2. Threshold effect analysis of TACE group in the derivation cohort using two-piece-wise linear regression. The predicted value at the point of $56 \%$ was $0.23(0.21,0.24)$. A log-likelihood ratio test was used to compare the one-line linear regression.

Fig A1. After propensity-matching treatment status (hepatic resection vs TACE) groups. Standardized differences of the 5 covariates that were included for estimating propensity scores were compared before and after weighting with a value of $<10 \%$ indicating between-group balance. $x 1=$ Age; $\mathrm{x} 2=\mathrm{PT} ; \mathrm{x} 3=$ Diameter of main tumor $(\mathrm{cm}) ; \mathrm{x} 4=$ Both lobe with lesion; $\mathrm{x} 5=$ No. of intrahepatic lesions. Standardized difference $=\operatorname{abs}(\mathrm{P} 1-\mathrm{P} 0) / \operatorname{sqrt}((\mathrm{P} 1 *(1-\mathrm{P} 1)+\mathrm{P} 0 *(1-\mathrm{P} 0)) / 2)$.

Fig A2. Overall mortality (OM)-free survival rate plotted against predicted probability of OM at $5 \mathrm{yr}$ in the IPTW cohort. Blue line indicates hepatic resection for primary treatment. Red line indicates TACE for primary treatment.

Fig A3. Number of patients needed to treat with hepatic resection plotted against the predicted probability of overall mortality (OM) at 5 yr in the IPTW cohort.

Table B1. Baseline characteristics between TACE and HR group in the secondary cohort. Table B1. Baseline characteristics between TACE and HR group in the secondary cohort.

Table B2. The multivariable analysis focusing on the secondary cohort. The secondary cohort excluded the patients with ablative therapies and surgical resection after 1 st line treatment. $\mathrm{AFP}=$ alpha-fetoprotein, $\mathrm{PT}=$ prothrombin time, $\mathrm{TBLT}=$ total bilirubin, $\mathrm{ALB}=$ albumin, $\mathrm{HR}=$ hepatic resection

Fig B1. Overall mortality (OM)-free survival rate plotted against predicted probability of OM at $5 \mathrm{yr}$ in the secondary cohort. The secondary cohort excluded the patients with ablative therapies and surgical resection after 1st line treatment. Blue line indicates hepatic resection for primary treatment. Red line indicates TACE for primary treatment.

Table B3. Threshold effect analysis of TACE group in the derivation cohort using two-piece-wise linear regression The secondary cohort excluded the patients with ablative therapies and surgical resection after 1 st line treatment. The predicted value at the point of $52 \%$ was $21 \%(95 \% \mathrm{CI}: 19 \%, 23 \%)$. A log-likelihood ratio test was used to compare the one-line linear regression.

Fig B2. Number of patients needed to treat with hepatic resection plotted against the predicted probability of overall mortality $(O M)$ at $5 \mathrm{yr}$ in the secondary cohort. The secondary cohort excluded the patients with ablative therapies and surgical resection after 1st line treatment. 
medRxiv preprint doi: https://doi.org/10.1101/2020.10.07.20166769; this version posted October 9,2020 . The copyright holder for this preprint (which was not certified by peer review) is the author/funder, who has granted medRxiv a license to display the preprint in It is made available under a CC-BY-NC-ND 4.0 International license .

Table 1. Baseline characteristics between TACE and HR group in the derivation cohort

\begin{tabular}{lccc}
\hline & \multicolumn{2}{c}{ Treatment } & \multirow{2}{*}{ P-value } \\
\cline { 2 - 3 } & TACE & HR & \\
\hline No. & 717 & 225 & 0.001 \\
Age & $53.9 \pm 12.3$ & $50.9 \pm 12.6$ & 0.802 \\
Gender & & & \\
$\quad$ male & $654(91.2 \%)$ & $204(90.7 \%)$ & \\
$\quad$ female & $63(8.8 \%)$ & $21(9.3 \%)$ & 0.104 \\
$\log _{10}$ AFP (ng/ml); missing $\mathrm{n}=49$ & $2.5 \pm 1.4$ & $2.4 \pm 1.5$ & 0.111 \\
$\log _{10}$ TBLT(umol/L); missing $\mathrm{n}=7$ & $1.3 \pm 0.2$ & $1.3 \pm 0.3$ & 0.215 \\
ALB (g/L); missing n=7 & $38.9 \pm 5.7$ & $38.3 \pm 5.4$ & 0.031 \\
PT (second); missing $\mathrm{n}=19$ & $12.3 \pm 1.3$ & $12.5 \pm 1.6$ & $<0.001$ \\
Diameter of main tumor(cm) & $7.4 \pm 3.7$ & $6.4 \pm 2.8$ & $<0.001$ \\
No. of intrahepatic lesions & & & \\
2 & $179(25.0 \%)$ & $121(53.8 \%)$ & \\
3 & $58(8.1 \%)$ & $21(9.3 \%)$ & \\
$>3$ & $480(66.9 \%)$ & $83(36.9 \%)$ & \\
Both lobe with lesions & & & \\
$\quad$ no & $255(35.5 \%)$ & $148(65.8 \%)$ & \\
$\quad$ yes & $462(64.5 \%)$ & $77(34.2 \%)$ & \\
HBV infection; missing $\mathrm{n}=97$ & & & \\
no & $18(2.8 \%)$ & $2(1.0 \%)$ & \\
$\quad$ yes & $622(97.2 \%)$ & $203(99.0 \%)$ & \\
\hline
\end{tabular}

$\mathrm{AFP}=$ alpha-fetoprotein, $\mathrm{PT}=$ prothrombin time, $\mathrm{TBLT}=$ total bilirubin, $\mathrm{ALB}=$ albumin, $\mathrm{HR}=$ hepatic resection. The chi-square test was performed for categorical measures and Kruskal-Wallis Test for continuous measures. *Fisher's exact probability test. 
medRxiv preprint doi: https://doi.org/10.1101/2020.10.07.20166769; this version posted October 9, 2020. The copyright holder for this preprint (which was not certified by peer review) is the author/funder, who has granted medRxiv a license to display the preprint in It is made available under a CC-BY-NC-ND 4.0 International license

Table 2. The multivariable analysis focusing on the derivation cohort

\begin{tabular}{|c|c|c|c|}
\hline & Statistics & Death & P-value \\
\hline \multicolumn{4}{|l|}{ Treatment } \\
\hline TACE & $717(76.11 \%)$ & Reference & \\
\hline HR & $225(23.89 \%)$ & $0.41(0.33,0.52)$ & $<0.0001$ \\
\hline Age & $53.22 \pm 12.45$ & $1.00(0.99,1.01)$ & 0.6612 \\
\hline \multicolumn{4}{|l|}{ Gender } \\
\hline male & $858(91.08 \%)$ & Reference & \\
\hline female & $84(8.92 \%)$ & $1.15(0.85,1.56)$ & 0.3546 \\
\hline ALB (g/L); missing $n=7$ & $38.73 \pm 5.66$ & $0.99(0.97,1.00)$ & 0.1248 \\
\hline PT (second); missing $n=19$ & $12.32 \pm 1.40$ & $1.07(1.00,1.14)$ & 0.0398 \\
\hline \multicolumn{4}{|l|}{ No. of intrahepatic lesions } \\
\hline 2 lession & $300(31.85 \%)$ & Reference & \\
\hline 3 lession & $79(8.39 \%)$ & $1.12(0.80,1.57)$ & 0.5162 \\
\hline$>3$ lession & $563(59.77 \%)$ & $1.59(1.31,1.93)$ & $<0.0001$ \\
\hline Diameter of main tumor $(\mathrm{cm})$ & $7.19 \pm 3.56$ & $1.15(1.13,1.18)$ & $<0.0001$ \\
\hline \multicolumn{4}{|l|}{ Both lobe with lesion } \\
\hline no & $403(42.78 \%)$ & Reference & \\
\hline yes & $539(57.22 \%)$ & $1.51(1.26,1.80)$ & $<0.0001$ \\
\hline $\log _{10}$ AFP $(\mathrm{ng} / \mathrm{ml}) ; \operatorname{missing} \mathrm{n}=49$ & $2.49 \pm 1.42$ & $1.21(1.14,1.29)$ & $<0.0001$ \\
\hline $\log _{10}$ TBLT(umol/L); missing $n=7$ & $1.28 \pm 0.25$ & $0.93(0.66,1.32)$ & 0.6888 \\
\hline
\end{tabular}

$\mathrm{AFP}=$ alpha-fetoprotein, $\mathrm{PT}=$ prothrombin time, $\mathrm{TBLT}=$ total bilirubin, $\mathrm{ALB}=$ albumin, $\mathrm{HR}=$ hepatic resection 
medRxiv preprint doi: https://doi.org/10.1101/2020.10.07.20166769; this version posted October 9, 2020. The copyright holder for this preprint (which was not certified by peer review) is the author/funder, who has granted medRxiv a license to display the preprint in It is made available under a CC-BY-NC-ND 4.0 International license .

Table 3. Threshold effect analysis of TACE group in the derivation cohort using two-piece-wise linear regression

\begin{tabular}{lll}
\hline & Unadjusted $\beta(95 \% \mathrm{CI})$ & P-value \\
\hline $\begin{array}{l}\text { The one-line linear model } \\
\text { The two-piece-wise linear model }\end{array}$ & $-0.71(-0.75,-0.67)$ & $<0.0001$ \\
$\quad<55 \%$ & $-0.96(-1.04,-0.88)$ & $<0.0001$ \\
$>55 \%$ & $-0.48(-0.56,-0.41)$ & $<0.0001$ \\
P for log-likelihood ratio test & & $<0.001$ \\
\hline
\end{tabular}

The predicted value at the point of 55\% was $20 \%(95 \mathrm{CI}: 19 \%, 22 \%)$. A log-likelihood ratio test was used to compare the one-line linear regression. 


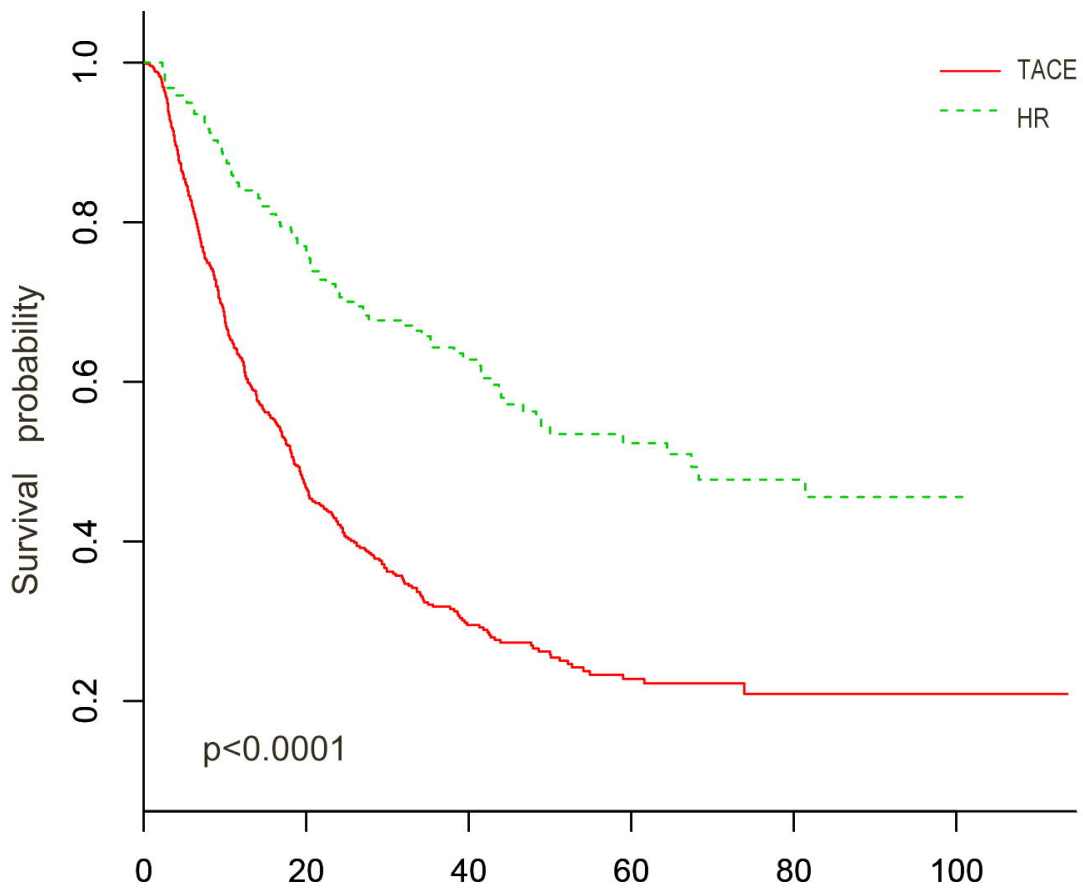

Overall Survival Time (months)

\begin{tabular}{|c|c|c|c|c|}
\hline 717 & 260 & 99 & 43 & 11 \\
\hline 225 & 149 & 80 & 46 & 22 \\
\hline
\end{tabular}




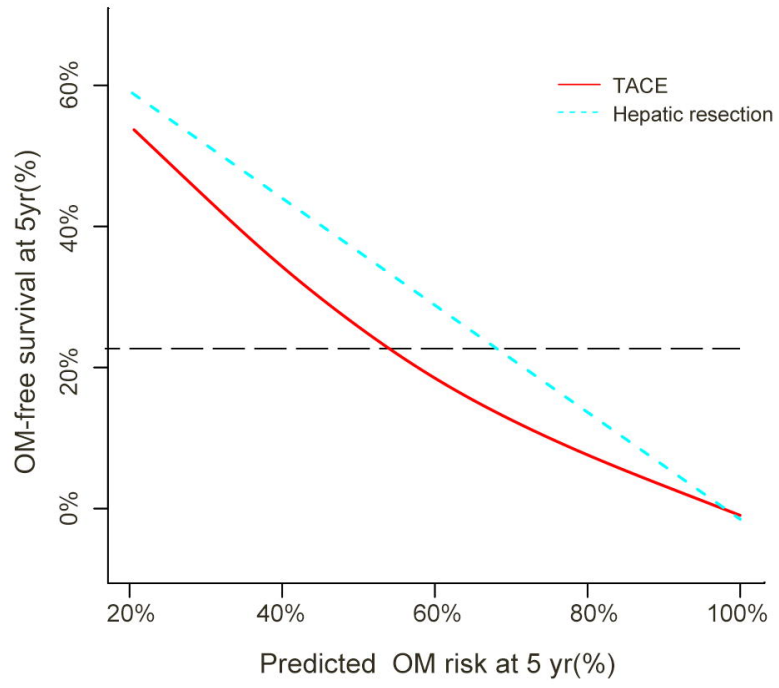




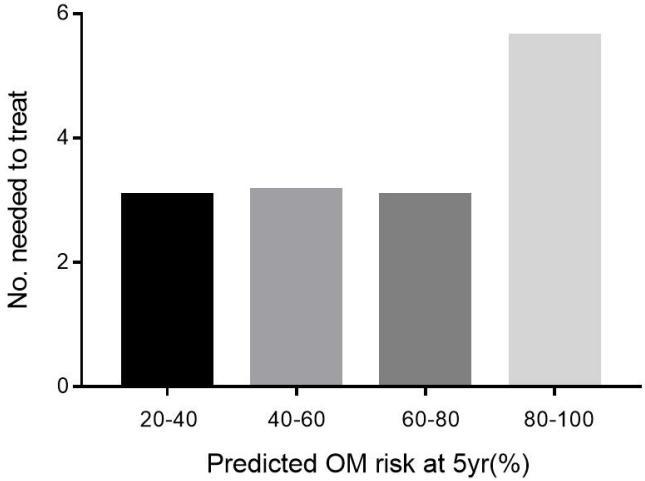

Hazard Ratio

0.40

0.41

0.40

0.61

$95 \% \mathrm{Cl}$ up

0.26

0.28

0.24

0.31

0.61

0.68

1.21

NTT

3.07

3.15

3.07

5.62 